\title{
Self-Reported Cognitive Impairment Across Racial/Ethnic Groups in the United States, National Health Interview Survey, $1997-2015$
}

\author{
Huabin Luo, $\mathrm{PhD}^{1}$; Gary Yu, $\mathrm{DrPH}^{2}$; Bei Wu, $\mathrm{PhD}^{2,3}$
}

\begin{abstract}
Accessible Version: www.cdc.gov/pcd/issues/2018/17_0338.htm
Suggested citation for this article: Luo H, Yu G, Wu B. SelfReported Cognitive Impairment Across Racial/Ethnic Groups in the United States, National Health Interview Survey, 1997-2015. Prev Chronic Dis 2018;15:170338. DOI: https://doi.org/10.5888/ pcd15.170338.
\end{abstract}

\section{PEER REVIEWED}

\section{Abstract}

\section{Introduction}

The primary objectives of this study were 1) to examine trends of self-reported cognitive impairment among 5 major racial/ethnic groups during 1997-2015 in the United States and 2) to examine differences in the trends across these groups.

\section{Methods}

Data were from the National Health Interview Survey (NHIS). The sample consisted of 155,682 people aged 60 or older. Respondents were asked to report whether any family member was "limited in any way because of difficulty remembering or because of experiencing periods of confusion." Race/ethnicity categories were non-Hispanic white, non-Hispanic black, Native American, Hispanic, and Asian. We applied hierarchical age-period-cohort cross-classified random-effects models for the trend analysis. All analyses accounted for the complex survey design of NHIS.

\section{Results}

The overall rate of self-reported cognitive impairment increased from $5.7 \%$ in 1997 to $6.7 \%$ in 2015 ( $P$ for trend $<.001$ ). Among non-Hispanic white respondents, the rate increased from $5.2 \%$ in 1997 to $6.1 \%$ in 2015 (slope $=0.14, P$ for trend $<.001$ ). We observed no significant trend in rate of cognitive impairment in oth- er groups. After we controlled for covariates, we found that Asian $(B=0.31)$, non-Hispanic black $(B=0.37)$, Hispanic $(B=0.25)$, and Native American $(B=0.87)$ respondents were more likely than non-Hispanic white respondents to report cognitive impairment $(P<.001$ for all $)$.

\section{Conclusion}

We found an increased rate of self-reported cognitive impairment in older adults of 5 major racial/ethnic groups from 1997 through 2015 in the United States. However, the rate of self-reported cognitive impairment was low, which may suggest underreporting. There is a need to further promote awareness of the disease among individuals, family members, and health care providers.

\section{Introduction}

The aging population is increasing rapidly in the United States. The size of the US population aged 65 or older is projected to be 88.5 million in 2050 , more than double the size of this population (40.2 million) in 2010 (1). The population of older adults will also become more racially and ethnically diverse. By 2050 , the proportion of white older adults will account for $77 \%$ of the population aged 65 or older, down from $87 \%$ in 2010 , whereas the proportion for black older adults will be $12 \%$ (9\% in 2010), Asian older adults $9 \%$ (3\% in 2010), and Hispanic older adults $20 \%$ (7\% in 2010) (1).

With the rapid increase in the population of older adults, the size of the population with cognitive impairment and dementia will expand (2). Approximately 5.5 million Americans had Alzheimer's disease in 2017. This number is expected to grow to 13.8 million by 2050 (3). The age-adjusted death rate of Alzheimer's disease in the United States increased by $54.5 \%$ from 1999 to 2014 , from 16.5 per 100,000 population to 25.4 per 100,000 population. Significant increases occurred in all age groups, both sexes, and all racial/ethnic groups (4). 
Cognitive impairment may be a precursor to dementia (5). Early detection of cognitive impairment would facilitate timely medical treatments, appropriate care planning, and prevention efforts, which would ultimately reduce health care costs. Data on self-reported cognitive impairment are limited (6-8). Most previous studies have evaluated cognitive impairment by using screening tests or clinical examination (9-11). Some studies reported racial/ ethnic disparities in cognitive impairment in the United States (12-14). Older African American adults are about twice as likely and older Hispanic adults are about 1.5 times as likely to have Alzheimer's disease or other dementias as older non-Hispanic white adults (15). An important limitation of previous research on cognitive functioning is that it focused mostly on 3 racial/ethnic groups (white, black, and Hispanic) or fewer (14). No studies have examined the rate and trend of cognitive impairment in Asian or Native American adults in the United States. Information on the cognitive health for subpopulations is needed for health planning and delivery of culturally competent services. Hence, new research is warranted to assess the rate of cognitive impairment in various racial/ethnic groups in the United States.

This study aimed to fill the gap in the literature by using data from a nationally representative population-based survey, the National Health Interview Survey (NHIS) (16). The objectives of the study were 1) to examine the trends in rate of self-reported cognitive impairment among American adults aged 60 or older in 5 major racial/ethnic groups from 1997 through 2015 and 2) to examine differences in trends of self-reported cognitive impairment across these racial/ethnic groups.

\section{Methods}

We collected data on the following racial/ethnic groups: non-Hispanic white, non-Hispanic black, Hispanic, Native American, and Asian. Data were from the NHIS, a cross-sectional household interview survey conducted annually by the National Center for Health Statistics, which is part of the Centers for Disease Control and Prevention (CDC). NHIS obtains information through in-person interviews with household respondents to monitor the health of the US population. The multistage area probability design provides a representative sample of the civilian noninstitutionalized population residing in the United States at the time of the interviews. The analytical sample for this study included 155,682 adults aged 60 or older in the NHIS adult samples from 1997 through 2015 .

The outcome variable was self-reported cognitive impairment. In the NHIS family health status and limitation questionnaire, respondents are asked whether anyone in the household has a limitation in his or her everyday activities (eg, activities of daily living, instrumental activities of daily living, play, school, and work; difficulties in walking or in remembering) as a result of a physical, mental, or emotional health problem. The responses may be selfreported or reported by an adult household member or by proxy for other household members not present at the interview. We classified a person as having cognitive impairment if the answer was yes to the question on "limited in any way because of difficulty remembering or because of experiencing periods of confusion." This measure provides reliable estimates of cognitive status (17). (Another related NHIS question asks about cognitive impairment due to senility; that is, a limitation due to senility, Alzheimer's disease, or another aging-related cognitive impairment. We did not use this measure in our analysis because of the small sample sizes, particularly for racial/ethnic minority groups.)

We used 3 sociodemographic variables as covariates: age (60-64 y, 65-69 y, 70-74 y, 75-79 y, 80-84 y, and $\geq 85$ y), sex (male or female), and marital status (married or living with partner vs otherwise). We also used 2 variables of socioeconomic status as covariates: education level (some college or more vs others) and family income level. Family income was defined as the ratio of total family income to the federal poverty level (FPL), which was calculated as the family's income in the most recent calendar year divided by the applicable poverty threshold based on the size of the family. We classified this poverty ratio variable into 4 categories: less than $150 \%$ of the FPL, $150 \%$ to $249 \%$ of the FPL, $250 \%$ to $499 \%$ of the FPL, and $500 \%$ or more of the FPL.

In addition, we used 2 health-related variables as covariates. We collected data on whether or not (yes or no) respondents self-reported the following 5 diseases: heart attack, diabetes, high blood pressure, coronary heart disease, and stroke. We also collected data on body mass index (BMI), defined as weight in kilograms divided by height in meters squared $\left(\mathrm{kg} / \mathrm{m}^{2}\right)$, and we used the following BMI categories (18): underweight $\left(<18.5 \mathrm{~kg} / \mathrm{m}^{2}\right)$, normal weight (18.5-24.9 kg/m ${ }^{2}$ ), overweight $\left(25.0-29.9 \mathrm{~kg} / \mathrm{m}^{2}\right)$, and obese $\left(\geq 30.0 \mathrm{~kg} / \mathrm{m}^{2}\right)$.

Period and birth cohort were also included as covariates. The period was the survey year - the 19 waves of NHIS surveys from 1997 through 2015. We created 9 birth cohorts with 5- or 6-year intervals from 1912-1917 to 1953-1957.

We first calculated the rate of cognitive impairment in the various age groups, survey periods, and birth cohorts in the 5 racial/ethnic groups and assessed the significance of the slopes of trend lines (19). Because of the small sample size of Native American adults in each wave of NHIS, we calculated 3-year moving average rates

\footnotetext{
The opinions expressed by authors contributing to this journal do not necessarily reflect the opinions of the U.S. Department of Health and Human Services, the Public Health Service, the Centers for Disease Control and Prevention, or the authors' affiliated institutions.
} 
of cognitive impairment (2-year at both end points: 1997-1998 for the first period, 2014-2015 for the last period, and 3-year for the middle periods), and we used the average of the survey weight variable according to 2 or 3 years included. In addition, we compared the slopes of trend lines of period (survey year) to assess the difference in the rate of change over time by using $t$ tests.

Second, because NHIS data are cross-sectional, to control for age, survey period, and birth cohort effects, we applied the hierarchical age-period-cohort (HAPC) cross-classified random-effects model (CCREM) (20) to examine the trends of cognitive impairment. Data analyses were conducted by using SAS PROC GLIMMIX (21) with DIST=binary. The HAPC-CCREM model can effectively estimate any random clustering effects at higher-level crossclassified units such as survey periods and birth cohorts (20). Predicted probability of self-reported cognitive impairment (controlling for all covariates) was estimated for the 5 racial/ethnic groups by age group and birth cohort. We used sampling weights in analyses. A more conservative level of significance was set at .01 , instead of the standard .05 level, to account for multiple pairwise comparisons to a reference category using a Bonferroni correction $(0.05 / 5=0.01)(22)$.

In the HAPC-CCREM model, age effects refer to variation associated with different age groups, reflect biological and social processes of aging internally to individuals, and represent developmental changes during the life course. Period effects refer to changes in social, economic, technological, or physical environments affecting all age groups simultaneously at the time health is measured. Finally, cohort effects refer to variation among persons in different birth cohorts. A person in a given birth cohort experiences the same historical and social events at various stages of his or her life course as other people in that birth cohort. Thus, not taking into account cohort effects would possibly lead to biased estimate of trends of social inequalities in the outcome of interest (20).

\section{Results}

Among the $5 \mathrm{racial} / \mathrm{ethnic}$ groups, the non-Hispanic white group was the oldest, and the Hispanic group the youngest. Asian respondents had the largest proportion of adults who had some college or more $(62.1 \%)$ and were married or living with a partner $(70.4 \%)$ (Table 1). Hispanic respondents had the lowest family income: $65.6 \%$ were in the first or second income categories. The rates of high blood pressure $(71.5 \%)$ and obesity $(38.4 \%)$ were highest among non-Hispanic black respondents. Native American respondents had the highest rates of heart attack $(14.2 \%)$, diabetes $(31.4 \%)$, coronary heart disease $(16.6 \%)$, and stroke $(10.9 \%)$.
The overall rate of self-reported cognitive impairment increased from 5.7\% (95\% confidence interval, 5.2\%-6.3\%) in 1997 to $6.7 \%$ $(6.1 \%-7.3 \%$ ) ( $P$ for trend $<.001$ ). The rate increased from $5.2 \%$ in 1997 to $6.1 \%$ in 2015 among non-Hispanic white respondents $(P$ for trend $<.001)$. We found no significant trends in cognitive impairment among non-Hispanic black, Native American, Hispanic, or Asian respondents (Table 2).

We found no significant differences in the rate of change in slopes between non-Hispanic white and non-Hispanic black respondents $(t=0.24, P=.81)$, non-Hispanic white and Hispanic respondents $(t=0.18, P=.86)$, or non-Hispanic white and Asian respondents $(t$ $=0.17, P=.10)$. We did not compare the slope of non-Hispanic white respondents and Native American respondents because rates for Native American respondents were calculated in 3-year moving averages.

Overall, the rate of cognitive impairment increased with age in all $5 \mathrm{racial} / \mathrm{ethnic}$ groups $(P<.01$ for all groups $)$, with a sharper increase in those 85 years or older (Figure 1). Across the 9 birth cohorts, the rate was lowest among non-Hispanic white respondents until the 1943-1947 birth cohort, when the rate among Asian respondents was similar to the rate among non-Hispanic white respondents (Figure 2).

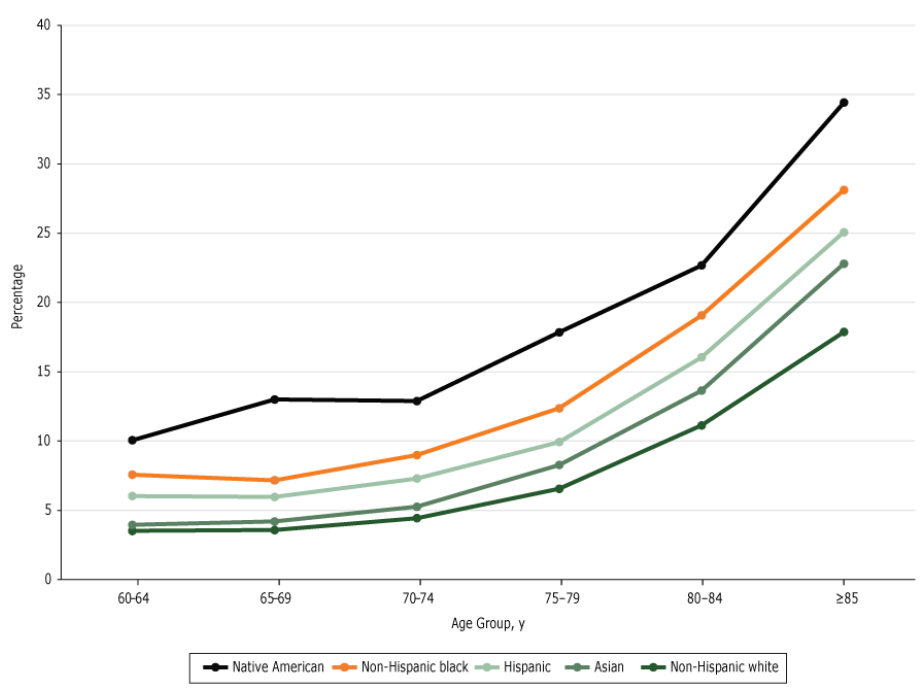

Figure 1. Predicted probability of reporting cognitive impairment, by age group. Data are from the National Health Interview Survey, 1997-2015.

The opinions expressed by authors contributing to this journal do not necessarily reflect the opinions of the U.S. Department of Health and Human Services, the Public Health Service, the Centers for Disease Control and Prevention, or the authors' affiliated institutions. 


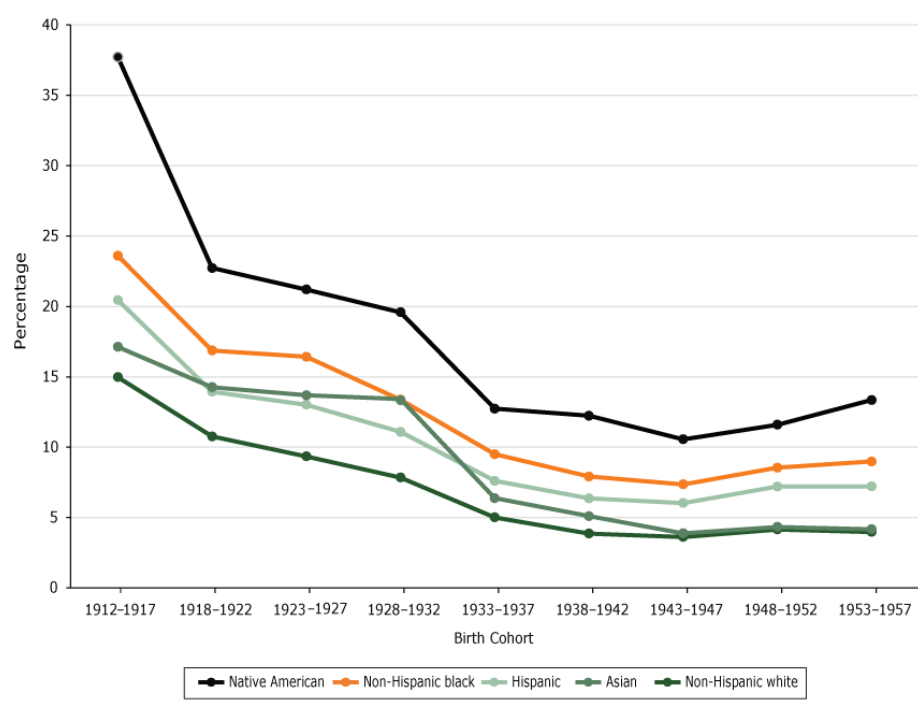

Figure 2. Predicted probability of reporting cognitive impairment, by birth cohort. Data are from the National Health Interview Survey, 1997-2015.

In the HAPC-CCREM model, compared with non-Hispanic white respondents, non-Hispanic black respondents $(\mathrm{B}=0.37, P<.001)$, Native American respondents $(\mathrm{B}=0.87, P<.001)$, Hispanic respondents $(\mathrm{B}=0.25, P<.001)$, and Asian respondents $(\mathrm{B}=0.31$, $P<.001)$ were more likely to report cognitive impairment (Table 3 ). Parameter estimates on all other covariates were significant ( $P$ $<.001)$ : lower education level; lower family income level; having a heart attack, diabetes, high blood pressure, coronary heart disease, or stroke; and underweight were all risk factors of cognitive impairment. The interaction term race/ethnicity by some college or more was significant for all groups, indicating that college education reduced the odds of having cognitive impairment, except for the Hispanic group.

Overall, the survey period had a significant random effect $(\mathrm{B}=$ $0.01, P=.001)$. The birth cohort 1918-1922 had negative effects, whereas the birth cohorts 1948-1952 and 1953-1957 had positive effects. However, the overall random cohort effects were not significant (Table 3).

\section{Discussion}

To our knowledge, our study is the first to provide a national trend estimate on self-reported cognitive impairment among non-Hispanic white, non-Hispanic black, Hispanic, Native American, and Asian adults aged 60 or older in the United States from 1997 to
2015. Our findings indicate a significant increasing trend in selfreported cognitive impairment. Racial/ethnic differences in self-reported cognitive impairment persisted throughout the study period; the rate of self-reported cognitive impairment was lowest among non-Hispanic white adults.

A study in 2014 analyzed the same NHIS data and found that cognitive impairment in adults aged 18 or older increased from $2.0 \%$ in 1998 to $3.3 \%$ in 2011 (8), but cognitive impairment was not a focus, and the study covered a shorter period (8).

It is interesting that our data showed an increasing trend in self-reported cognitive impairment in adults aged 60 or older. Other recent studies that used data from cognitive tests and clinical assessments found a declining trend in dementia in the United States $(9,23)$. A report in 2016 on the Framingham Heart Study showed that the temporal trends of incidence of dementia among participants aged 60 or older declined by about $20 \%$ per decade between 1977 and 2008: the 5-year age- and sex-adjusted dementia rates were 3.6\% during 1977-1983, 2.8\% during 1986-1991, $2.2 \%$ during $1992-1998$, and $2.0 \%$ during 2004-2008 (10). In addition, an analysis of Health and Retirement Study (HRS) data found that the prevalence of cognitive impairment with no dementia in adults aged 65 or older decreased significantly from $21.2 \%$ in 2000 to $18.8 \%$ in 2012 (9). The HRS assesses cognitive function by using a multidimensional measure based on a modified version of the Telephone Interview Cognitive Screen and tests of immediate and delayed verbal recalls (9).

Nevertheless, it is not appropriate to make direct comparisons among these studies because of differences in definitions, operationalization of cognitive impairment, and study designs. The significant increasing trend of self-reported cognitive impairment found in our study might suggest that awareness of cognitive impairment has improved in the United States, especially in recent years (ie, after 2010). The heightened public attention to and interest in Alzheimer's disease might have contributed to the increased awareness. Indeed, efforts to improve awareness and perception of cognitive health has been ongoing, including CDC's and the Alzheimer's Association's Health Brain Initiative, the Alzheimer's Association's Maintain Your Brain workshops and community-based demonstration projects to promote cognitive health, and initiatives by the American Association of Retired Persons (24).

Several factors should be considered when interpreting our findings on the increasing trend of cognitive impairment. First, regardless of the increasing trend, an overall rate, ranging from $4.7 \%$ to

\footnotetext{
The opinions expressed by authors contributing to this journal do not necessarily reflect the opinions of the U.S. Department of Health and Human Services, the Public Health Service, the Centers for Disease Control and Prevention, or the authors' affiliated institutions.
} 
$6.7 \%$ during the study period, may be underreported. When we analyzed data on a subset of our sample (those aged 65 or older), the rate of self-reported cognitive impairment was $6.3 \%$ in 2000 and $7.5 \%$ in 2012 . These rates are still lower than the rates shown by HRS data for the same age group $(21.2 \%$ in 2000 and $18.8 \%$ in 2012) (9).

Second, we found an increasing trend in cognitive impairment only among non-Hispanic white adults. Overall, racial/ethnic minority groups in our study had higher rates of self-reported cognitive impairment than did the non-Hispanic white group. Public education is needed to promote awareness of this disease, especially among racial/ethnic minority groups, who may have different cultural beliefs and perceptions of disease and aging than nonHispanic white groups (25). Members of racial/ethnic minority groups may be less likely to seek treatment for psychiatric symptoms because of lack of access to care and/or cultural stigmatization (26). Moreover, racial/ethnic minority populations may be less likely than the non-Hispanic white population to accept treatment for depression (27). If the symptoms of depression are left untreated, cognitive health and quality of life may decline.

Third, the HAPC model results showed racial/ethnic disparities: racial/ethnic minority adults were more likely than non-Hispanic white adults to report cognitive impairment. These findings are consistent with previous findings indicating that white adults were less likely to have cognitive impairment than black or Hispanic adults $(12,13)$. A recent study that used HRS data found that Hispanic and black adults had lower levels of cognitive function than white adults: in a cognitive test having a maximum score of 27 points, Hispanic adults scored 13.7, black adults scored 13.3, and white adults scored 16.3 (12). In addition, consistent with prior research, our study showed that diseases such as diabetes and stroke were associated with higher odds of self-reported cognitive impairment (28). The persistent racial/ethnic disparities in chronic disease risk factors may partially account for the higher rate of cognitive impairment among racial/ethnic minority groups. National Health and Nutrition Examination Survey data for 1988-1994 to 1999-2004 showed that racial/ethnic disparities in cardiovascular disease risk factors between non-Hispanic whites and non-Hispanic blacks and between non-Hispanic whites and Mexican Americans did not improve; for some health outcomes, such as obesity and hypercholesterolemia, the gap even widened (29).

No overall birth cohort effects were observed in our study, although the cohort 1918-1922 was less likely than other cohorts to self-report cognitive impairment, whereas the 2 youngest cohorts (ie, 1948-1952 and 1953-1957) were more likely than other cohorts to self-report cognitive impairment. Finally, we found a significant interaction effect between education and race (except in
Hispanics), indicating a similar effect of education on cognitive impairment across groups. Education levels have increased in the United States in the past several decades (30), and education is shown to protect against cognitive decline (31). A higher level of education may contribute to the ability to recognize cognitive decline. Education could explain why younger birth cohorts were more likely than older cohorts in our study to report cognitive impairment. Thus, our study indicates that the role of education in self-reported cognitive impairment is twofold: a higher level of education protects against cognitive decline and contributes to greater self-awareness of cognitive impairment.

The data used in our study have several limitations. First, the data were self-reported and thus are subject to reporting bias. Respondents may intentionally withhold information because of stigma, or they may not have been able to provide a reliable answer because they were cognitively impaired. Self-reported cases of cognitive impairment cannot be validated through clinical assessment. Also, proxy-reported data could introduce bias. Proxies might misreport the information for various reasons, including lack of knowledge and stigma. However, studies showed that proxy-reported data on cognition status of family members may be more reliable than self-reported data (32). Second, the sample size for the Native American group was small for calculating yearly estimates. Future surveys should increase the sample size for the Native American group because Native Americans are at higher risk of many chronic diseases that are associated with cognitive impairment, including cardiovascular disease and diabetes (14). Third, our study did not include residents in long-term care facilities, who are more likely to be cognitively impaired than community-dwelling older adults.

From 1997 to 2015, NHIS data showed that the overall rate of self-reported cognitive impairment increased among the 5 major racial/ethnic groups in the United States. However, by racial/ethnic group, the increasing trend was significant only among the non-Hispanic white group. Significant racial/ethnic disparities persisted during the study period. Our findings may reflect an increased self-awareness of cognitive impairment in the United States. They also underscore the need to further promote awareness of cognitive impairment, especially among racial/ethnic minority populations. Health education is needed for individuals, family members, and health care providers to improve awareness and knowledge of signs and early symptoms of Alzheimer's disease and other forms of dementia.

The opinions expressed by authors contributing to this journal do not necessarily reflect the opinions of the U.S. Department of Health and Human Services, the Public Health Service, the Centers for Disease Control and Prevention, or the authors' affiliated institutions. 


\section{Acknowledgments}

We did not have financial support for this project, nor do we have any conflicts of interest to disclose.

\section{Author Information}

Corresponding Author: Bei $\mathrm{Wu}, \mathrm{PhD}$, Rory Meyers College of Nursing, New York University, New York, NY 10010. Telephone: 212-992-5951. Email: bei.wu@nyu.edu.

Author Affiliations: ${ }^{1}$ Department of Public Health, East Carolina University, Greenville, North Carolina. ${ }^{2}$ Rory Meyers College of Nursing, New York University, New York, New York. ${ }^{3} \mathrm{NYU}$ Aging Incubator, New York, New York.

\section{References}

1. Vincent GK, Velkoff VA. The next four decades. The older population in the United States: 2010 to 2050. Current population reports. Washington (DC): US Census Bureau; 2010. p. 25-1138.

2. Plassman BL, Langa KM, Fisher GG, Heeringa SG, Weir DR, Ofstedal MB, et al. Prevalence of cognitive impairment without dementia in the United States. Ann Intern Med 2008; 148(6):427-34.

3. Alzheimer's Association. 2017Alzheimer's disease facts and figures. http://www.alz.org/facts/overview.asp. Accessed May 6, 2017.

4. Taylor CA, Greenlund SF, McGuire LC, Lu H, Croft JB. Deaths from Alzheimer's disease - United States, 1999-2014. MMWR Morb Mortal Wkly Rep 2017;66(20):521-6.

5. Leifer BP. Early diagnosis of Alzheimer's disease: clinical and economic benefits. J Am Geriatr Soc 2003;51(5 Suppl):S281-8.

6. Adams M, Deokar A, Anderson L, Edwards V; Centers for Disease Control and Prevention (CDC). Self-reported increased confusion or memory loss and associated functional difficulties among adults aged $\geq 60$ years -21 States, 2011 . MMWR Morb Mortal Wkly Rep 2013;62(18):347-50.

7. Marlow NM, Slate EH, Bandyopadhyay D, Fernandes JK, Leite RS. Health insurance status is associated with periodontal disease progression among Gullah African-Americans with type 2 diabetes mellitus. J Public Health Dent 2011; 71(2):143-51.

8. Iezzoni LI, Kurtz SG, Rao SR. Trends in U.S. adult chronic disability rates over time. Disabil Health J 2014;7(4):402-12.
9. Langa KM, Larson EB, Crimmins EM, Faul JD, Levine DA, Kabeto MU, et al. A comparison of the prevalence of dementia in the United States in 2000 and 2012. JAMA Intern Med 2017;177(1):51-8.

10. Satizabal CL, Beiser AS, Chouraki V, Chêne G, Dufouil C, Seshadri S. Incidence of dementia over three decades in the Framingham Heart Study. N Engl J Med 2016;374(6):523-32.

11. Langa KM, Larson EB, Karlawish JH, Cutler DM, Kabeto MU, Kim SY, et al. Trends in the prevalence and mortality of cognitive impairment in the United States: is there evidence of a compression of cognitive morbidity? Alzheimers Dement 2008;4(2):134-44.

12. Díaz-Venegas C, Downer B, Langa KM, Wong R. Racial and ethnic differences in cognitive function among older adults in the USA. Int J Geriatr Psychiatry 2016;31(9):1004-12.

13. Sloan FA, Wang J. Disparities among older adults in measures of cognitive function by race or ethnicity. J Gerontol B Psychol Sci Soc Sci 2005;60(5):242-50.

14. Mehta KM, Yeo GW. Systematic review of dementia prevalence and incidence in United States race/ethnic populations. Alzheimers Dement 2017;13(1):72-83.

15. Alzheimer's Association. 2010 Alzheimer's disease facts and figures. Alzheimers Dement 2010;6(2):158-94.

16. National Center for Health Statistics. About the National Health Interview Survey. https://www.cdc.gov/nchs/nhis/ about_nhis.htm. Accessed July 20, 2017.

17. Bernstein AB, Remsburg RE. Estimated prevalence of people with cognitive impairment: results from nationally representative community and institutional surveys. Gerontologist 2007;47(3):350-4.

18. Centers for Disease Control and Prevention. How is BMI calculated? https://www.cdc.gov/healthyweight/assessing/bmi/ adult_bmi/index.html. Accessed July 20, 2017.

19. Paternoster R, Brame R, Mazerolle P, Piquero A. Using the correct statistical test for the equality of regression coefficients. Criminology 1998;36(4):859-66.

20. Yang Y, Land K. Age-period-cohort analysis: new models, methods, and empirical applications. London (UK): CRC Press; 2013.

21. Littell RC, Milliken GA, Stroup WW, Wolfinger RD, Schabenberger O. SAS for mixed models. 2nd edition. Cary (NC): SAS Institute Inc; 2006.

22. Fleiss JL. The design and analysis of clinical experiments. New York (NY): John Wiley \& Sons; 1986.

23. Sheffield KM, Peek MK. Changes in the prevalence of cognitive impairment among older Americans, 1993-2004: overall trends and differences by race/ethnicity. Am J Epidemiol 2011;174(3):274-83.

\footnotetext{
The opinions expressed by authors contributing to this journal do not necessarily reflect the opinions of the U.S. Department of Health and Human Services, the Public Health Service, the Centers for Disease Control and Prevention, or the authors' affiliated institutions.
} 
24. Anderson LA, Day KL, Beard RL, Reed PS, Wu B. The public's perceptions about cognitive health and Alzheimer's disease among the U.S. population: a national review. Gerontologist 2009;49(Suppl 1):S3-11.

25. Chin AL, Negash S, Hamilton R. Diversity and disparity in dementia: the impact of ethnoracial differences in Alzheimer disease. Alzheimer Dis Assoc Disord 2011;25(3):187-95.

26. Anglin DM, Alberti PM, Link BG, Phelan JC. Racial differences in beliefs about the effectiveness and necessity of mental health treatment. Am J Community Psychol 2008; 42(1-2):17-24.

27. Cooper LA, Gonzales JJ, Gallo JJ, Rost KM, Meredith LS, Rubenstein LV, et al. The acceptability of treatment for depression among African-American, Hispanic, and white primary care patients. Med Care 2003;41(4):479-89.

28. de la Torre JC. Cardiovascular risk factors promote brain hypoperfusion leading to cognitive decline and dementia. Cardiovasc Psychiatry Neurol 2012;2012:367516.

29. Romero CX, Romero TE, Shlay JC, Ogden LG, Dabelea D. Changing trends in the prevalence and disparities of obesity and other cardiovascular disease risk factors in three racial/ ethnic groups of USA adults. Adv Prev Med 2012; 2012:172423.

30. Federal Interagency Forum on Aging-Related Statistics. Older Americans 2012: key indicators of well-being. Washington (DC): US Government Printing Office. https://agingstats.gov/ docs/PastReports/2012/OA2012.pdf. Accessed May 10, 2017.

31. Vemuri P, Lesnick TG, Przybelski SA, Machulda M, Knopman DS, Mielke MM, et al. Association of lifetime intellectual enrichment with cognitive decline in the older population. JAMA Neurol 2014;71(8):1017-24.

32. Edwards VJ, Anderson LA, Deokar AJ. Proxy reports about household members with increased confusion or memory loss, 2011 Behavioral Risk Factor Surveillance System. Prev Chronic Dis 2015;12:E47.

The opinions expressed by authors contributing to this journal do not necessarily reflect the opinions of the U.S. Department of Health and Human Services, the Public Health Service, the Centers for Disease Control and Prevention, or the authors' affiliated institutions. 


\section{Tables}

Table 1. Sample Characteristics, by Race/Ethnicity, National Health Interview Survey, 1997-2015

\begin{tabular}{|c|c|c|c|c|c|c|}
\hline Variable & $\begin{array}{c}\text { Non-Hispanic } \\
\text { White, \% } \\
(n=116,445)\end{array}$ & $\begin{array}{c}\text { Non-Hispanic } \\
\text { Black, \% } \\
(n=19,975)\end{array}$ & $\begin{array}{c}\text { Native American, } \\
\% \\
(n=796)\end{array}$ & $\begin{array}{l}\text { Hispanic, \% } \\
(n=15,553)\end{array}$ & $\begin{array}{c}\text { Asian, } \% \\
(n=2,913)\end{array}$ & $P$ Value $^{\mathrm{a}}$ \\
\hline \multicolumn{7}{|l|}{ Age, y } \\
\hline $60-64$ & 28.4 & 32.5 & 35.0 & 32.8 & 32.9 & \multirow{6}{*}{$<.001$} \\
\hline $65-69$ & 22.5 & 24.0 & 22.8 & 25.6 & 25.3 & \\
\hline $70-74$ & 18.5 & 18.7 & 19.7 & 18.6 & 18.3 & \\
\hline $75-79$ & 12.6 & 11.0 & 9.4 & 11.2 & 10.4 & \\
\hline $80-84$ & 9.3 & 7.3 & 7.9 & 6.7 & 6.4 & \\
\hline$\geq 85$ & 8.7 & 6.6 & 5.1 & 5.3 & 6.7 & \\
\hline Female & 55.0 & 58.9 & 51.7 & 55.7 & 51.8 & $<.001$ \\
\hline Married or living with partner & 63.1 & 42.1 & 51.0 & 58.3 & 70.4 & $<.001$ \\
\hline Some college or more & 48.5 & 34.3 & 39.2 & 24.9 & 62.1 & $<.001$ \\
\hline \multicolumn{7}{|c|}{ Ratio of family income to federal poverty level } \\
\hline$<150 \%$ & 17.4 & 41.5 & 38.6 & 42.3 & 22.9 & \multirow{4}{*}{$<.001$} \\
\hline $150 \%-249 \%$ & 22.0 & 21.9 & 23.5 & 23.3 & 16.0 & \\
\hline $250 \%-499 \%$ & 33.6 & 24.1 & 22.8 & 23.3 & 28.8 & \\
\hline$\geq 500 \%$ & 27.1 & 12.6 & 15.1 & 11.1 & 32.3 & \\
\hline \multicolumn{7}{|l|}{ Chronic disease } \\
\hline Heart attack & 10.2 & 8.4 & 14.2 & 7.5 & 6.4 & $<.001$ \\
\hline Diabetes & 15.7 & 28.3 & 31.4 & 27.3 & 20.6 & $<.001$ \\
\hline High blood pressure & 53.8 & 71.5 & 62.9 & 55.2 & 55.9 & $<.001$ \\
\hline Coronary heart disease & 13.4 & 11.0 & 16.6 & 10.3 & 10.3 & $<.001$ \\
\hline Stroke & 7.1 & 9.9 & 10.9 & 7.0 & 6.0 & $<.001$ \\
\hline \multicolumn{7}{|l|}{ Body mass index, $\mathrm{kg} / \mathrm{m}^{2}$} \\
\hline$<18.5$ & 2.0 & 1.5 & 2.8 & 1.1 & 3.4 & \multirow{4}{*}{$<.001$} \\
\hline Normal (18.5-24.9) & 33.8 & 24.8 & 26.8 & 26.4 & 53.9 & \\
\hline Overweight (25.0-29.9) & 36.8 & 35.3 & 33.4 & 40.5 & 30.5 & \\
\hline Obese $(\geq 30.0)$ & 27.5 & 38.4 & 37.0 & 32.0 & 12.1 & \\
\hline
\end{tabular}

${ }^{a}$ According to $x^{2}$ tests. 
Table 2. Weighted Prevalence of Cognitive Impairment, by Racial/Ethnic Group, National Health Interview Survey,1997-2015

\begin{tabular}{|c|c|c|c|c|c|c|}
\hline \multirow[b]{2}{*}{ Year } & \multicolumn{6}{|c|}{ Percentage } \\
\hline & Non-Hispanic White & Non-Hispanic Black & Native American ${ }^{a}$ & Hispanic & Asian & Overall \\
\hline 1997 & 5.2 & 9.1 & NA & 9.3 & NA & 5.7 \\
\hline 1998 & 5.0 & 8.0 & 6.5 & 6.2 & 7.4 & 5.4 \\
\hline 1999 & 4.3 & 7.5 & 9.1 & 6.5 & 3.7 & 4.7 \\
\hline 2000 & 5.0 & 10.2 & 12.7 & 7.3 & 9.4 & 5.6 \\
\hline 2001 & 5.6 & 11.1 & 20.6 & 8.9 & 6.1 & 6.3 \\
\hline 2002 & 6.0 & 8.6 & 20.6 & 7.5 & 14.7 & 6.5 \\
\hline 2003 & 6.0 & 11.4 & 13.7 & 7.0 & 7.3 & 6.6 \\
\hline 2004 & 5.9 & 8.3 & 7.6 & 8.1 & 7.6 & 6.3 \\
\hline 2005 & 6.2 & 9.9 & 9.6 & 8.3 & 7.8 & 6.7 \\
\hline 2006 & 5.7 & 9.8 & 13.5 & 7.5 & 6.2 & 6.2 \\
\hline 2007 & 6.2 & 12.3 & 14.1 & 8.1 & 8.1 & 6.9 \\
\hline 2008 & 5.3 & 9.1 & 10.3 & 6.1 & 7.0 & 5.8 \\
\hline 2009 & 6.1 & 11.4 & 10.1 & 6.6 & 4.4 & 6.6 \\
\hline 2010 & 6.0 & 8.4 & 11.4 & 8.4 & 5.6 & 6.4 \\
\hline 2011 & 6.5 & 10.2 & 13.3 & 8.7 & 10.7 & 7.2 \\
\hline 2012 & 5.8 & 9.5 & 15.3 & 9.3 & 6.1 & 6.5 \\
\hline 2013 & 6.3 & 10.8 & 16.0 & 8.0 & 6.1 & 6.9 \\
\hline 2014 & 6.2 & 9.7 & 16.9 & 8.9 & 5.0 & 6.8 \\
\hline 2015 & 6.1 & 9.2 & 16.2 & 8.7 & 5.3 & 6.7 \\
\hline$P$ value for trend & $<.001$ & .30 & .27 & .15 & .28 & $<.001$ \\
\hline
\end{tabular}


Table 3. Hierarchical Age-Period-Cohort Cross-Classified Model Results of Factors Associated With Self-Reported Cognitive Impairment, National Health Interview Survey,1997-2015

\begin{tabular}{|c|c|c|}
\hline Variable & B (Standard Error) & $P$ Value \\
\hline \multicolumn{3}{|l|}{ Fixed effects } \\
\hline Intercept & $-2.15(0.05)$ & $<.001$ \\
\hline Age (centered) & $0.04(0)$ & $<.001$ \\
\hline Age $^{2}$ & $0(0)$ & $<.001$ \\
\hline \multicolumn{3}{|l|}{ Sex } \\
\hline Male & \multicolumn{2}{|r|}{ Reference } \\
\hline Female & $-0.07(0)$ & $<.001$ \\
\hline \multicolumn{3}{|l|}{ Marital status } \\
\hline Not married or living with partner & \multicolumn{2}{|r|}{ Reference } \\
\hline Married or living with partner & $-0.33(0)$ & $<.001$ \\
\hline \multicolumn{3}{|l|}{ Race/ethnicity } \\
\hline Non-Hispanic white & \multicolumn{2}{|r|}{ Reference } \\
\hline Non-Hispanic black & $0.37(0)$ & $<.001$ \\
\hline Native American & $0.87(0.01)$ & $<.001$ \\
\hline Hispanic & $0.25(0)$ & $<.001$ \\
\hline Asian & $0.31(0.01)$ & $<.001$ \\
\hline \multicolumn{3}{|l|}{ Education } \\
\hline$<$ Some college or more & \multicolumn{2}{|r|}{ Reference } \\
\hline Some college or more & $-0.20(0)$ & $<.001$ \\
\hline \multicolumn{3}{|c|}{ Ratio of family income to federal poverty level } \\
\hline$<150 \%$ & \multicolumn{2}{|r|}{ Reference } \\
\hline $150 \%-249 \%$ & $-0.33(0)$ & $<.001$ \\
\hline $250 \%-499 \%$ & $-0.43(0)$ & $<.001$ \\
\hline$\geq 500 \%$ & $-0.83(0)$ & $<.001$ \\
\hline \multicolumn{3}{|l|}{ Body mass index, $\mathrm{kg} / \mathrm{m}^{2}$} \\
\hline Underweight (<18.5) & \multicolumn{2}{|r|}{ Reference } \\
\hline Normal (BMI 18.5-24.9) & $-0.65(0)$ & $<.001$ \\
\hline Overweight (BMI 25.0-29.9) & $-0.93(0)$ & $<.001$ \\
\hline Obese $(\geq 30.0)$ & $-0.74(0)$ & $<.001$ \\
\hline \multicolumn{3}{|l|}{ Chronic disease $^{a}$} \\
\hline Heart attack & $0.16(0)$ & $<.001$ \\
\hline Diabetes & $0.47(0)$ & $<.001$ \\
\hline High blood pressure & $0.09(0)$ & $<.001$ \\
\hline Coronary heart disease & $0.32(0)$ & $<.001$ \\
\hline Stroke & $1.44(0)$ & $<.001$ \\
\hline \multicolumn{3}{|l|}{ Race/ethnicity $\times$ college or more } \\
\hline Non-Hispanic white $\times$ college or more & & Reference \\
\hline
\end{tabular}

${ }^{\text {a }}$ Reference group for each category is absence of the disease. 
(continued)

Table 3. Hierarchical Age-Period-Cohort Cross-Classified Model Results of Factors Associated With Self-Reported Cognitive Impairment, National Health Interview Survey,1997-2015

\begin{tabular}{|c|c|c|}
\hline Variable & B (Standard Error) & $P$ Value \\
\hline Non-Hispanic black $\times$ college or more & $-0.06(0.01)$ & $<.001$ \\
\hline Native American $\times$ college or more & $-0.20(0.02)$ & $<.001$ \\
\hline Hispanic $\times$ college or more & $-0.01(0.01)$ & .13 \\
\hline Asian $\times$ college or more & $-0.27(0.01)$ & $<.001$ \\
\hline \multicolumn{3}{|l|}{ Random effects } \\
\hline Survey period & $0.01(0)$ & .001 \\
\hline 1997 & $-0.10(0.03)$ & .001 \\
\hline 1998 & $-0.17(0.03)$ & $<.001$ \\
\hline 1999 & $-0.26(0.03)$ & $<.001$ \\
\hline 2000 & $-0.14(0.03)$ & $<.001$ \\
\hline 2001 & $0.03(0.03)$ & .35 \\
\hline 2002 & $0.03(0.03)$ & .32 \\
\hline 2003 & $0.05(0.03)$ & .04 \\
\hline 2004 & $-0.03(0.03)$ & .21 \\
\hline 2005 & $0.12(0.03)$ & $<.001$ \\
\hline 2006 & $-0.01(0.03)$ & .58 \\
\hline 2007 & $0.15(0.03)$ & $<.001$ \\
\hline 2008 & $-0.18(0.03)$ & $<.001$ \\
\hline 2009 & $0.04(0.03)$ & .12 \\
\hline 2010 & $0.07(0.03)$ & .02 \\
\hline 2011 & $0.13(0.03)$ & $<.001$ \\
\hline 2012 & $0.05(0.03)$ & .08 \\
\hline 2013 & $0.09(0.03)$ & .001 \\
\hline 2014 & $0.13(0.03)$ & $<.001$ \\
\hline 2015 & $0.00(0.03)$ & .98 \\
\hline Cohort & $0.01(0.01)$ & .02 \\
\hline $1912-1917$ & $0.01(0.04)$ & .78 \\
\hline 1918-1922 & $-0.15(0.04)$ & $<.001$ \\
\hline $1923-1927$ & $-0.06(0.04)$ & .14 \\
\hline $1928-1932$ & $-0.07(0.04)$ & .06 \\
\hline $1933-1937$ & $0.00(0.04)$ & .93 \\
\hline $1938-1942$ & $-0.07(0.04)$ & .07 \\
\hline $1943-1947$ & $-0.03(0.04)$ & .45 \\
\hline 1948-1952 & $0.19(0.04)$ & $<.001$ \\
\hline 1953-1957 & $0.18(0.04)$ & $<.001$ \\
\hline
\end{tabular}

${ }^{a}$ Reference group for each category is absence of the disease. 